\title{
Microparticles and Fibrinolysis
}

\author{
Loris Vallier, PharmD ${ }^{1}$ Sylvie Cointe, PharmD, $\mathrm{PhD}^{1,2}$ Romaric Lacroix, PharmD, $\mathrm{PhD}^{1,2}$ \\ Amandine Bonifay, PharmD ${ }^{1}$ Coralie Judicone, $\mathrm{MS}^{2}$ Françoise Dignat-George, PharmD, $\mathrm{PhD}^{1,2}$ \\ Hau C. Kwaan, MD, FRCP ${ }^{3}$
}

1 VRCM, UMR_S1076, UFR de Pharmacie, Aix-Marseille Université, INSERM, Marseille, France

${ }^{2}$ Department of Hematology and Vascular Biology, CHU La Conception, APHM, Marseille, France

3 Division of Hematology/Oncology, Northwestern University Feinberg

School of Medicine, Chicago, Illinois

\begin{abstract}
Address for correspondence Hau C. Kwaan, MD, FRCP, Division of Hematology/Oncology, Northwestern University Feinberg School of Medicine, Chicago, IL (e-mail: h-kwaan@northwestern.edu).
\end{abstract}

\author{
Keywords \\ - extracellular vesicles \\ - cancer \\ - fibrinolysis \\ - hemostasis \\ - microparticles
}

\begin{abstract}
Microparticles (MPs) are submicronic vesicles which are formed by budding of the cellular membrane of virtually any cell type in response to cell activation or apoptosis. Both circulating MPs and MPs generated within tissues harbor molecules with a large repertoire of biological activities and transfer material to target cells. Depending on their cellular origin, the stimuli triggering their formation, or their localization, they may participate in the maintenance of organ or vascular homeostasis as well as inducing dysfunction. MPs have mostly been described as having procoagulant properties. However, the fact that some MP subsets are able to efficiently generate plasmin suggests that the role of MPs in hemostasis is more complex than initially thought. In this review, we summarize key findings showing that MPs provide a heterogeneous catalytic surface for plasmin generation, according to their cellular origin. We further address the specific features of the MP-dependent fibrinolytic system. Potential consequences of this MP-associated fibrinolytic activity in pathology are illustrated in cancer.
\end{abstract}

All normal eukaryotic and prokaryotic cells and cancer cells release extracellular vesicles (EVs) in response to stress, activation, or apoptosis. ${ }^{1}$ These EVs are heterogeneous, with three main types: exosomes, microvesicles/microparticles (MPs), and apoptotic bodies. They differ by their sizes, the mechanism of their production mechanism, as well as their composition and functions ${ }^{2,3}$ : MPs are submicronic vesicles which are formed by calcium-dependent cellular events such as remodeling of membrane phospholipids, cytoskeleton cleavage, and contraction of the actin cytoskeleton. Their membrane consists of a phospholipid bilayer enriched in negative phospholipids such as phosphatidylserine (PS) on the external leaflet. MPs exhibit surface proteins and glycoproteins representative of their parental cells. These proteins could vary depending on the stimuli which triggered their formation. Despite the lack of nucleus, they can vectorize nucleic acids (mRNA and miRNA). MPs are present in all body fluids: blood, urine, cerebrospinal fluid, saliva, pleural fluid, synovial fluids, and vitreous humor. The majority of MPs detected in peripheral blood are derived from platelets and erythrocytes as well as leukocyte, endothelial cells, or nonhematopoietic cells such as syncytiotrophoblasts and circulating tumor cells. MPs have to be distinguished from exosomes, which are small vesicles measuring between 30 and $100 \mathrm{~nm} .{ }^{4,5}$ Exosomes are formed in endosomes which become multivesicular bodies, fused with cellular membrane and releasing their content into the extracellular environment. Usually, exosomes do not express anionic phospholipids on their surface and are enriched in molecules of the tetraspanin family, such as CD63 and CD81. Apoptotic bodies, unlike other vesicles, are formed exclusively from programmed cell death 
(apoptosis). ${ }^{6}$ Generally, these bodies measure between 500 and $4000 \mathrm{~nm}$ and are characterized by the presence of nuclear material such as histones and DNA. ${ }^{7}$

Because of the variety of molecules that MPs can transfer to target cells, they display a large repertoire of biological activities, among which is participation in the maintenance of vascular homeostasis as well as inducing vascular dysfunction. Over the past decades, MPs have been shown to play a role in hemostasis, inflammatory response, vascular tone, immune responses, angiogenesis, and tumor growth. ${ }^{8,9}$ Among these functions, the role of MPs in hemostasis has been extensively documented. ${ }^{10}$ MPs have been described as primarily having procoagulant properties because of two components of the MP's bilayer. First, MPs expose anionic phospholipids such as PS on their outer leaflet, which assemble calcium-dependent coagulation factors on the surface of MPs, thus forming tenase and/or prothrombinase complexes, leading to thrombin formation. The second component is tissue factor (TF), a surfacebound, transmembrane glycoprotein which triggers the coagulation cascade in a factor VII-dependent manner. Not all MPs display PS or TF; thus, their capacity to generate thrombin is heterogeneous depending on their cellular origin and the stimulus which triggered their formation. For instance, erythrocyte-MPs (Ery-MPs) derived from transfused red blood cells generated significantly more thrombin than platelet-derived MPs (PMPs) in $\beta$-thalassemic major patients. ${ }^{11}$ The thrombin generation capacity of PMPs is also increased when these patients were splenectomized independently of the platelet and PMP numbers, suggesting that splenectomy impacts the PMP quality and their ability to generate thrombin.

Published data showed that anticoagulant proteins are present on the surface of MPs, ${ }^{10}$ including thrombomodulin on monocyte-derived MPs, endothelial protein C receptor on endothelial-derived MPs (EMPs), TF pathway inhibitor on MPs derived from cancer cells, ${ }^{12-14}$ endothelial cells, ${ }^{15}$ platelets, ${ }^{16,17}$ smooth muscle cells, ${ }^{18}$ syncytiotrophoblasts, ${ }^{19}$ and monocytes, ${ }^{20}$ while Ery-MPs can bind activated protein $C$ and protein S. ${ }^{21}$ Moreover, data showing that some MP subpopulations are able to efficiently generate plasmin suggest that the role of MPs on hemostasis is more complex than initially thought. ${ }^{22}$

In this review, we summarize the key findings showing that MPs heterogeneously behave as an efficient surface for plasmin generation depending on their cellular origin. In addition, we address the specificities of this MP-dependent fibrinolytic system. Potential consequences of this MP-associated fibrinolytic activity in pathology are illustrated in patients with solid tumors and acute promyelocytic leukemia (APL).

\section{Microparticle-Dependent Fibrinolytic System}

\section{Diversity of Microparticles and Their Capacity to Generate Plasmin}

Initially, the presence of both active metalloproteinases and urokinase plasminogen activator (uPA) on the MP surface suggests a possible activation of the system on MPs derived from tumor cells (tum-MPs). ${ }^{23}$ Several studies published since 1994 have confirmed the presence of these proteolytic enzymes, both in vitro and ex vivo, on tum-MPs isolated from culture supernatant of human tumor cell lines or ascites fluid from patients with ovarian cancer. ${ }^{23-29}$ Lytic bands on fibrinagar zymography indicated a fibrinolytic activity of tum-MPs dependent not only on uPA but also on the tissue plasminogen activator ( $t-P A)$ as shown on a carcinoma line of prostate cancer by zymography. Inhibitors that regulate the plasmingenerating system such as plasminogen activator inhibitor-1 (PAI-1) also found on the surface of tum-MPs. ${ }^{28}$

In hematopoietic cells, plasmin generation was first described in vitro on MPs derived from human microvascular endothelial cells after stimulation with tumor necrosis factor- $\alpha$. Plasminogen binds to the MP surface by C-terminal lysine residues on proteins such as $\alpha$-enolase. Plasminogen activation involves uPA and its receptor UPAR, whose presence on the EMPs has been demonstrated by enzyme-linked immunosorbent assay, zymography, electron microscopy, and flow cytometry. ${ }^{22}$ Thus, plasminogen can be activated on the surface of EMPs in a dose-dependent, saturable, and specific manner as evidenced by zymography or chromogenic tests. ${ }^{22}$ Plasminogen can also be activated to plasmin by EMPs generated without specific cell stimulation. Plasmin generating capacity has been shown on EMPs generated from mature primary endothelial cells from different organs (kidney: renal artery; heart: heart coronary artery; and skin: human dermal microvascular endothelial cells) and endothelial progenitors isolated from cord blood. MPs generated from human leukocytes (LMPs; neutrophils, monocytes, and lymphocytes) also have this property. ${ }^{30}$

Plasmin-generating capacity was found on MPs isolated from human plasma by ultracentrifugation or immunomagnetic separation. Interestingly, in contrast to their procoagulant activity, not all MPs have a plasmin-generation activity. It is mainly seen in circulating EMPs and LMPs but not in EryMPs and PMPs. ${ }^{30}$ More accurately, although most MPs can bind plasminogen and provide an efficient surface for plasminogen activation, only EMPs and LMPs contain plasminogen activators. Depending on their cellular origin, different plasminogen activators are present on MPs. LMPs express UPA and its receptor urokinase plasminogen activator receptor (uPAR) while EMPs contain t-PA and the t-PA/PAI-1 complex. ${ }^{23}$ The presence of plasminogen receptors has been found on the surface of MPs, such as annexin II on circulating MPs from APL patients. ${ }^{31}$ Conversely, some subpopulations such as PMPs may negatively regulate the MP-plasmin generation capacity being enriched in PAI- $1 .^{32}$

Thus, leukocyte, endothelial, and tumoral MP subsets contain both procoagulant and profibrinolytic enzymatic complexes (-Fig. 1). The net result of these activities depends on the balance between the procoagulant and profibrinolytic molecules (coagulation/fibrinolytic balance). This balance may be altered according to the MP subset and factors that trigger their formation (-Fig. 2).

\section{Specific Features of the Microparticle-Dependent Fibrinolytic System}

MPs represent a newly identified pool of circulating plasminogen activators. The majority of uPAR on the EMP surface do not have any ligand bound in the circulation. Exogenous uPA can 


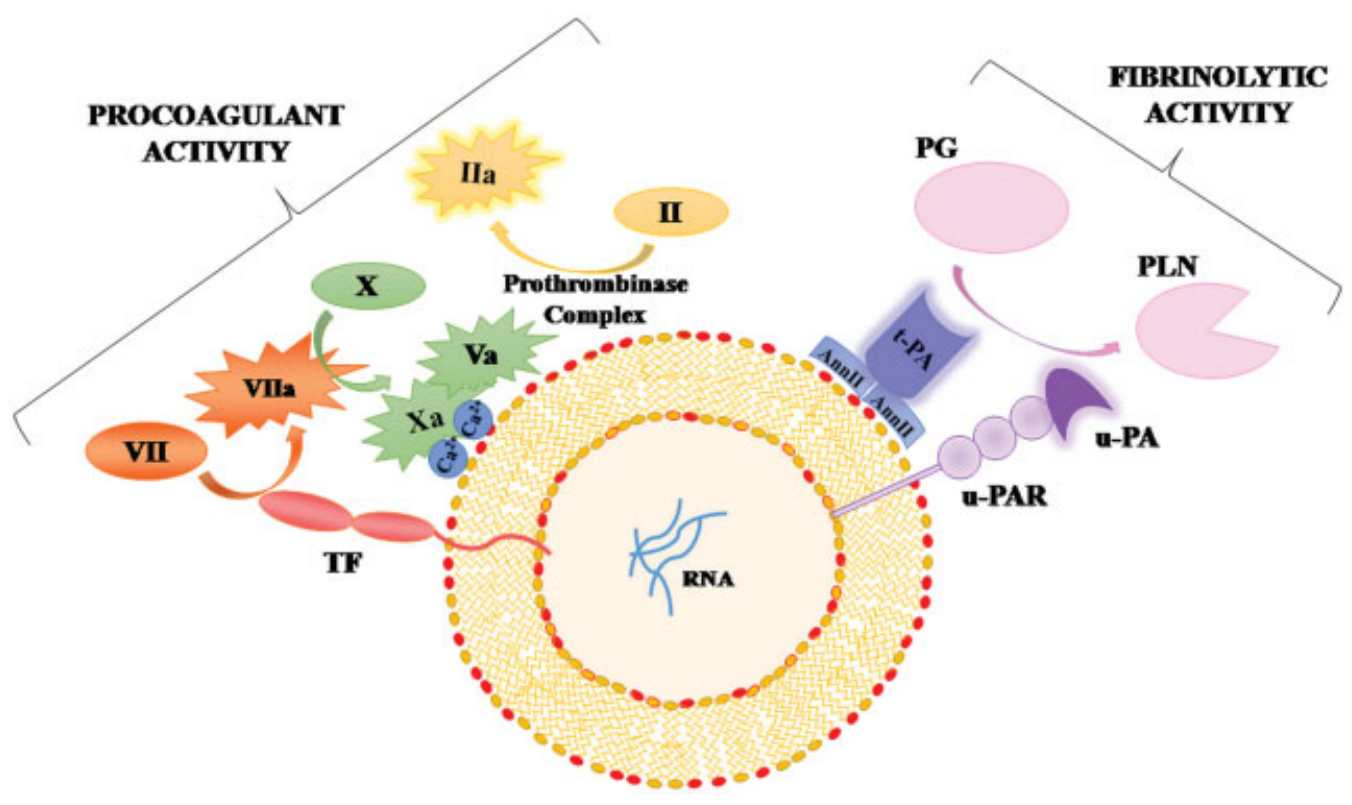

Fig. 1 MPs carry both procoagulant and fibrinolytic activities. MPs carry a procoagulant activity dependent on both tissue factor and phosphatidylserine and a fibrinolytic activity dependent on u-PA/u-PAR and t-PA. Ann II, annexin A2; PG, plasminogen; PLN, plasmin; RNA, ribonucleic acid; TF, tissue factor; t-PA, tissue plasminogen activator; u-PA, urokinase-type plasminogen activator; u-PAR, uPA receptor.

specifically bind to these receptors, which amplifies plasmin generation. $^{22}$ These data suggest that uPA released into the local environment can be transferred to the MPs. This mechanism may have implications in tumorigenesis, in which uPA is believed to play an important role. Furthermore, these MPs are able to activate plasminogen bound to fibrin, platelets, and extracellular matrix. ${ }^{32}$ Indeed, the uPA-uPAR system does not require plasminogen to be present on the same surface as its activator. Conversely this process is not observed with MPs bearing t-PA. ${ }^{32}$

Because plasminogen can bind MPs, on which plasminogen activators are also in abundance, MPs represent a new surface to efficiently generate plasmin. ${ }^{31}$ Once formed, plasmin remains partially attached to the MP surface 22 and can be transferred by circulation to other locations. Interestingly, in contrast to the soluble plasmin, the bound plasmin may be partially protected at the MP surface from inhibitors of the soluble phase such as $\alpha 2$-antiplasmin which can no longer interact with the K1 (Kringle 1) and K4 domains of plasmin. ${ }^{33}$ Moreover, because of their negative charge and their expression of adhesive molecules such as integrins or P-selectin glycoprotein ligand-1, MPs can bind to activated endothelial cells and platelets ${ }^{13,34,35}$ and

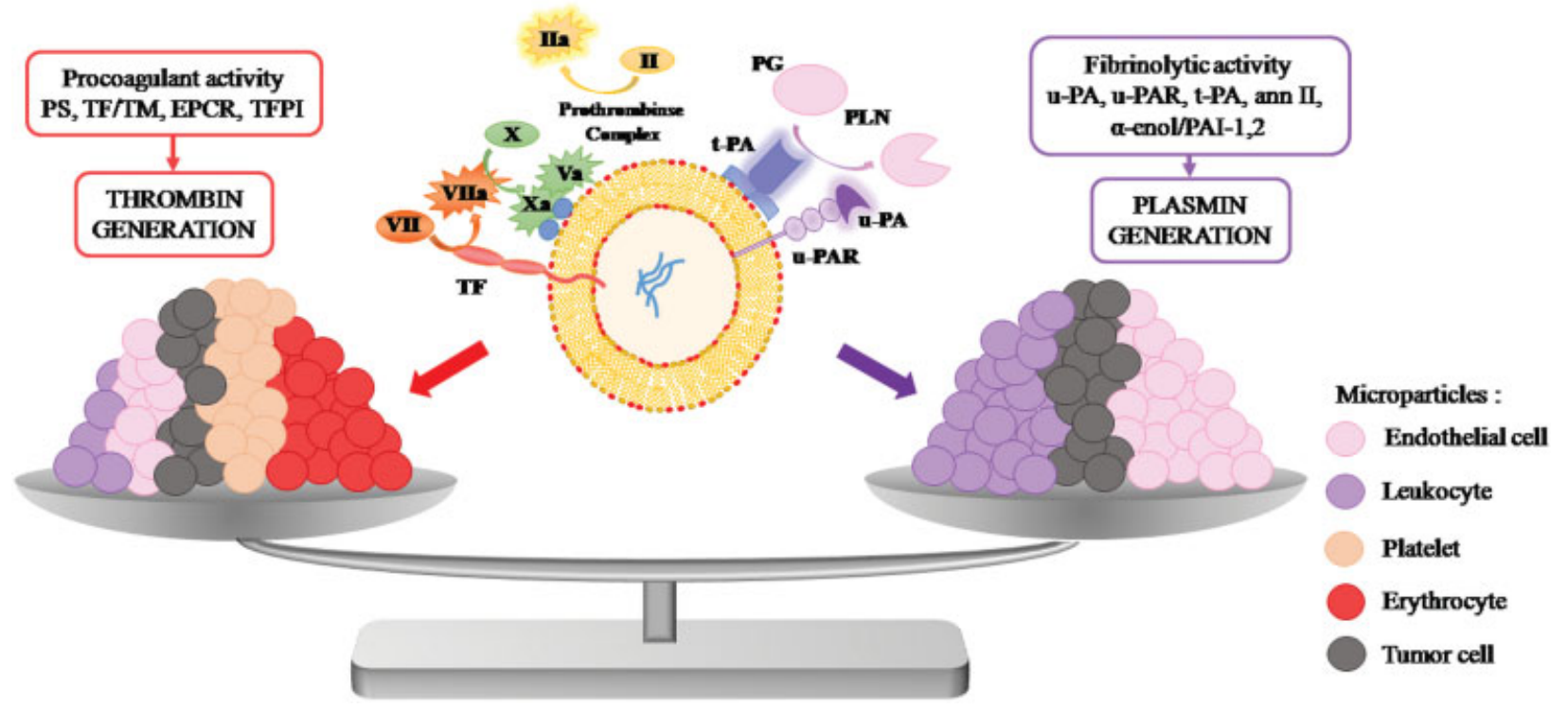

Fig. 2 MP-dependent coagulation/fibrinolytic balance. The MP-dependent coagulation/fibrinolytic balance varies according to the MP subsets. $\alpha$ enol, $\alpha$-enolase; EPCR, endothelial protein-C receptor; MP, microparticles; PAI-1, -2, plasminogen activators inhibitor-1, -2; PS, phosphatidylserine; TF, tissue factor; TFPI, tissue factor pathway inhibitor; TM, thrombomodulin; t-PA, tissue plasminogen activator; u-PA, urokinase-type plasminogen activator; u-PAR, u-PA receptor. 
therefore may incorporate plasminogen activator within the thrombus.

Thus, these data demonstrated that MPs participate in fibrinolysis; however, the degree of contribution of the MPdependent plasmin generation capacity compared with that of the soluble phase needs to be further investigated.

\section{Microparticles, Fibrinolysis, and Implications in Cancer}

An MP-dependent plasmin generation capacity is measurable in plasma from healthy donors. This activity is modulated in pathological conditions in which increased levels of LMPs and EMPs have been reported, such as atherosclerosis, thrombotic thrombocytopenic purpura, and antiphospholipid syndrome. $^{30}$ This fibrinolytic activity may reflect a leuko-endothelial activation associated with inflammatory processes. This activity is also found in biological liquid from cancer patients in which the MP-dependent plasmin generation capacity may represent a new potential biomarker as discussed below in solid tumor and APL.

\section{Solid Tumors}

Cancer is associated with a hypercoagulable state, and an elevated risk of thrombosis has an adverse effect on the morbidity and mortality. ${ }^{36,37}$ Cancer patients have high levels of circulating procoagulant MPs. ${ }^{38} \mathrm{~A}$ challenging question is whether these MPs can be used as an independent predictor of thrombosis in cancer patients. Results from a few longitudinal clinical studies are promising, ${ }^{39-41}$ but large-scale prospective studies are needed to determine the true value of MPs as a biomarker of thrombotic risk for a particular individual. It is as yet unclear whether the lack of definitive data on the predictive value of MPs on thrombosis risk in patients with solid tumors is the result of current technical concerns and limited standardization, or whether the predictive value of MPs depends on the origin and characteristics of the MPs. As EMPs, LMPs, and tum-MPs can either promote or inhibit coagulation and fibrinolysis, the thrombotic risk associated with cancer will be determined by the coagulation/fibrinolytic balance (-Fig. $\mathbf{3}$ ).

Besides being a potential regulator of the increased risk of thrombosis in patients with cancer, the fibrinolytic potential of tum-MPs is associated with increased cellular invasiveness and metastasis. It has been shown that vesicle-associated uPA promotes invasion of prostate cancer cell lines through modification of adhesive and proteolytic properties of tumor cells. ${ }^{28}$ Moreover, as demonstrated by Graves et al, MPs extracted from ascites in ovarian cancer stimulate cellular invasion and may account for the extremely aggressive metastatic behavior exhibited by these tumors. ${ }^{29}$ Interestingly, another study demonstrated that EVs from a pancreatic adenoma cell line bearing u-PAR, metalloproteinase- 2 and -9 cooperate with CD44v6 which plays an important role in cell motility through hyaluronic acid binding or association with integrins, cytoskeletal proteins, and metalloproteinases contributing to metastasis. ${ }^{42}$ Thus, the fibrinolytic system vectorized by MPs contributes to the dissemination of tumor by promoting matrix remodeling.

\section{Acute Promyelocytic Leukemia}

Coagulopathy and hemorrhagic complications are major presenting features in acute APL. This type of leukemia is characterized by a chromosomal translocation $t(15 ; 17)$ encoding the formation of a PML-RAR fusion protein, and

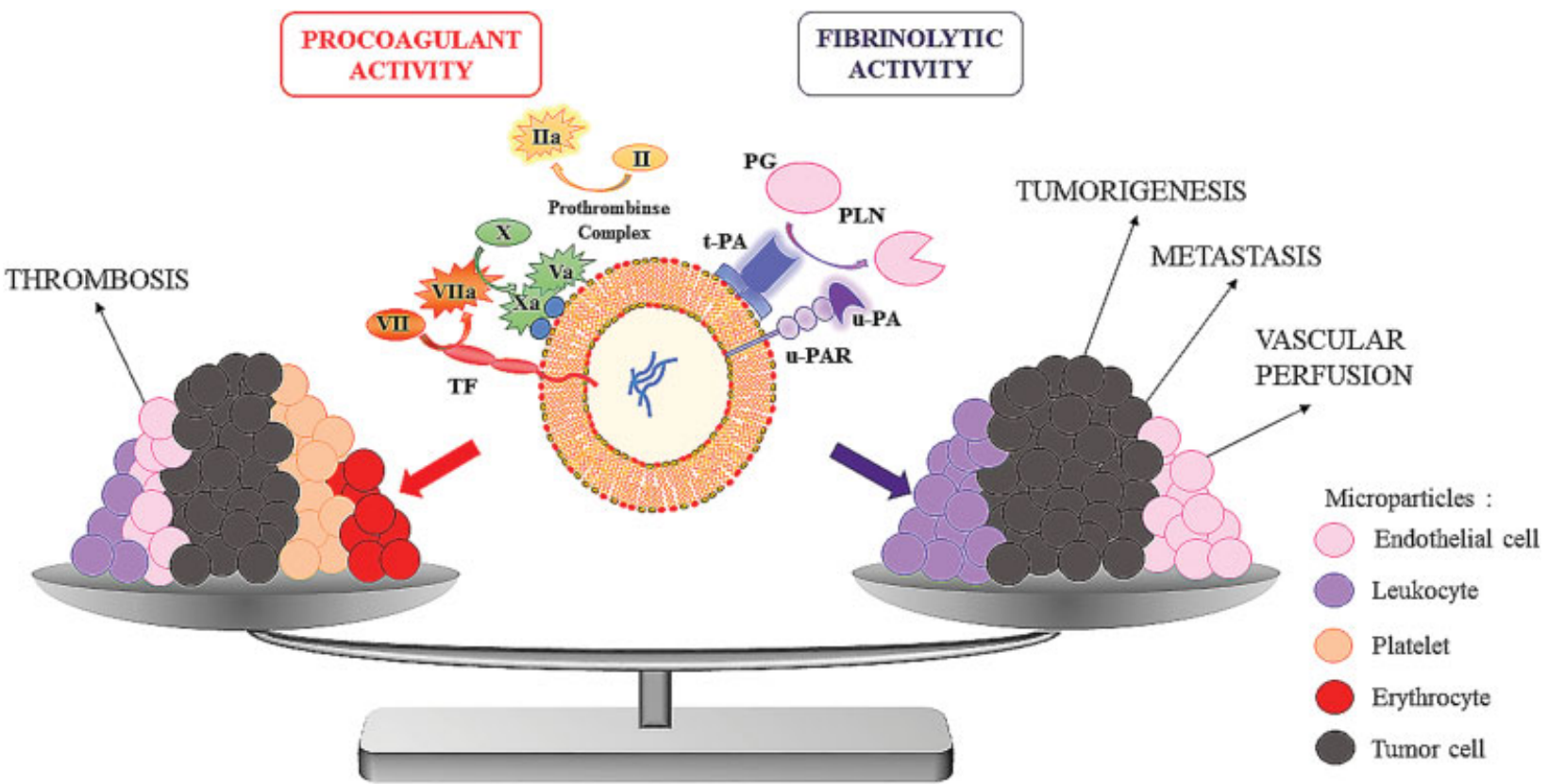

Fig. 3 MP-dependent coagulation/fibrinolytic balance in cancer. The thrombotic risk associated with cancer or the maintenance of the vascular perfusion may be determined by the MP-dependent coagulation/fibrinolytic balance. The fibrinolytic activity of MPs also contributes to tumorigenesis and metastasis. PG, plasminogen; PLN, plasmin; TF, tissue factor; t-PA, tissue plasminogen activator; u-PA, urokinase-type plasminogen activator; uPAR, u-PA receptor. 
resulting in the arrest of the differentiation of the promyelocytes. Differentiation therapy with all-trans retinoic acid (ATRA) or arsenic trioxide can achieve $>90 \%$ remission after induction therapy. ${ }^{43-45}$ However, the unique coagulopathy stands in the way of achieving a complete cure for this condition, with an early mortality rate up to $10 \%$ within the first 30 days of diagnosis, mainly due to bleeding complications. ${ }^{46,47}$ The laboratory picture at presentation is one of activated coagulation with increased levels of fibrinopeptide A, prothrombin fragment $1+2$ and thrombin-antithrombin complexes, with an increase in fibrin degradation products such as D-dimer and decreased fibrinogen level indicative of a consumptive coagulopathy. ${ }^{48-50}$

In essence, the pathogenesis of the coagulopathy of APL is, in part, a disseminated intravascular coagulation (DIC) caused by increased expression of TF by the leukemia promyelocytes. ${ }^{51}$ In addition, the fibrinolytic system is abnormal with increased t-PA, $\mathrm{uPA}$, and plasmin, and decreased PAI- 1 and $\alpha 2$-antiplasmin. ${ }^{50-54}$ The excessive fibrinolysis in APL is distinct from that seen as secondary response to DIC, because of these additional features: (1) both t-PA and uPA are increased ${ }^{52,55}$; (2) increased expression of annexin A2-S100A10 complex, a receptor for plasminogen and t-PA, was found on APL promyelocytes ${ }^{56,57}$ and (3) the activity of thrombin activable fibrinolytic inhibitor, an inhibitor of fibrinolysis, is reduced by as much as $60 \%{ }^{58}$ These findings were observed respectively on cell surface of the human APL cell line NB4 and of the APL promyelocytes in peripheral blood and bone marrow, as well as in conditioned medium of NB4 cultures and patient plasma.

The changes in fibrinolytic factors have also been found in MPs. Fibrinolytic factors are present in those MPs derived from both NB4 cells, and the leukemic myeloid (CD33) cells in patients. ${ }^{59,60}$ Using flow cytometry, ${ }^{60}$ antigens of TF, t-PA, annexin A2, uPA, uPAR, and PAI-1 were found to be present in MPs derived from CD33 positive cells prepared from APL patients. ${ }^{60}$ The levels of TF, t-PA, annexin A2 and PAI- 1 were much higher than those in healthy controls, while levels of uPA and UPAR were not. Remarkably, longitudinal observations revealed that these increased levels returned to normal at the time of remission following differentiation therapy with ATRA. ${ }^{60}$

When t-PA and PAI-1 in the MPs were tested for their functional activities by chromogenic methods, their levels were same as healthy controls. The absence of functional activity of the t-PA could be due to its binding to annexin A2/S100 protein or to complex formation with PAI-1. In the case of UPA, both the free form and uPA-PAI- 1 complex were present. MPs were also able to generate plasmin. Ongoing studies indicate that there is a correlation of the amount of plasmin generated with clinical events of bleeding. ${ }^{61}$ Thus in APL, MPs participate in the pathogenesis of the coagulopathy and the altered fibrinolysis.

\section{Conclusion}

Beyond their well-described procoagulant property, accumulated data have shown that MPs selectively shed by endothelial cells, leukocytes, and tumor cells bind plasminogen and vectorize plasminogen activators. These novel properties identify MPs as efficient catalytic surfaces for plasmin gener- ation. The existence of MP-dependent fibrinolytic potential in the circulation or in body fluids raises the question about the physiological relevance of this activity. However, further studies will be necessary to determine the extent in which, in vivo, MPs contribute to these pathophysiological mechanisms and how this recently reported blood-borne proteolytic properties identify MPs as a new biomarker in specific clinical situations such as cancer.

\section{References}

1 Akers JC, Gonda D, Kim R, Carter BS, Chen CC. Biogenesis of extracellular vesicles (EV): exosomes, microvesicles, retroviruslike vesicles, and apoptotic bodies. J Neurooncol 2013;113(1):1-11

2 Piccin A, Murphy WG, Smith OP. Circulating microparticles: pathophysiology and clinical implications. Blood Rev 2007;21(3):157-171

3 Zwicker JI. Tissue factor-bearing microparticles and cancer. Semin Thromb Hemost 2008;34(2):195-198

4 Théry C, Ostrowski M, Segura E. Membrane vesicles as conveyors of immune responses. Nat Rev Immunol 2009;9(8):581-593

5 De Toro J, Herschlik L, Waldner C, Mongini C. Emerging roles of exosomes in normal and pathological conditions: new insights for diagnosis and therapeutic applications. Front Immunol 2015;6:203

6 Ihara T, Yamamoto T, Sugamata M, Okumura H, Ueno Y. The process of ultrastructural changes from nuclei to apoptotic body. Virchows Arch 1998;433(5):443-447

7 Taylor RC, Cullen SP, Martin SJ. Apoptosis: controlled demolition at the cellular level. Nat Rev Mol Cell Biol 2008;9(3):231-241

8 Chou J, Mackman N, Merrill-Skoloff G, Pedersen B, Furie BC, Furie B. Hematopoietic cell-derived microparticle tissue factor contributes to fibrin formation during thrombus propagation. Blood 2004;104(10):3190-3197

9 Camussi G, Deregibus MC, Bruno S, Cantaluppi V, Biancone L. Exosomes/microvesicles as a mechanism of cell-to-cell communication. Kidney Int 2010;78(9):838-848

10 Owens AP III, Mackman N. Microparticles in hemostasis and thrombosis. Circ Res 2011;108(10):1284-1297

11 Agouti I, Cointe S, Robert S, et al. Platelet and not erythrocyte microparticles are procoagulant in transfused thalassaemia major patients. Br J Haematol 2015;171(4):615-624

12 Zarfati M, Katz T, Avivi I, Brenner B, Aharon A. PO-45 - The role of microvesicles in multiple myeloma progression. Thromb Res 2016;140(Suppl 1):S193

13 Mezouar S, Darbousset R, Dignat-George F, Panicot-Dubois L, Dubois C. Inhibition of platelet activation prevents the P-selectin and integrin-dependent accumulation of cancer cell microparticles and reduces tumor growth and metastasis in vivo. Int $\mathrm{J}$ Cancer 2015;136(2):462-475

14 Lwaleed BA, Lam L, Lasebai M, Cooper AJ. Expression of tissue factor and tissue factor pathway inhibitor in microparticles and subcellular fractions of normal and malignant prostate cell lines. Blood Coagul Fibrinolysis 2013;24(3):339-343

15 Kushak RI, Nestoridi E, Lambert J, Selig MK, Ingelfinger JR, Grabowski EF. Detached endothelial cells and microparticles as sources of tissue factor activity. Thromb Res 2005;116(5):409-419

16 Maroney SA, Haberichter SL, Friese P, et al. Active tissue factor pathway inhibitor is expressed on the surface of coated platelets. Blood 2007;109(5):1931-1937

17 Keuren JFW, Magdeleyns EJ, Govers-Riemslag JW, Lindhout T, Curvers J. Effects of storage-induced platelet microparticles on the initiation and propagation phase of blood coagulation. Br J Haematol 2006;134(3):307-313

18 Brisset A-C, Terrisse A-D, Dupouy D, et al. Shedding of active tissue factor by aortic smooth muscle cells (SMCs) undergoing apoptosis. Thromb Haemost 2003;90(3):511-518 
19 Aharon A, Tamari T, Brenner B. Monocyte-derived microparticles and exosomes induce procoagulant and apoptotic effects on endothelial cells. Thromb Haemost 2008;100(5):878-885

20 Angelillo-Scherrer A. Leukocyte-derived microparticles in vascular homeostasis. Circ Res 2012;110(2):356-369

21 Koshiar RL, Somajo S, Norström E, Dahlbäck B. Erythrocytederived microparticles supporting activated protein C-mediated regulation of blood coagulation. PLoS ONE 2014;9(8):e104200

22 Lacroix R, Sabatier F, Mialhe A, et al. Activation of plasminogen into plasmin at the surface of endothelial microparticles: a mechanism that modulates angiogenic properties of endothelial progenitor cells in vitro. Blood 2007;110(7):2432-2439

23 Ginestra A, Monea S, Seghezzi G, et al. Urokinase plasminogen activator and gelatinases are associated with membrane vesicles shed by human HT1080 fibrosarcoma cells. J Biol Chem 1997; 272(27):17216-17222

24 Ginestra A, La Placa MD, Saladino F, Cassarà D, Nagase H, Vittorelli ML. The amount and proteolytic content of vesicles shed by human cancer cell lines correlates with their in vitro invasiveness. Anticancer Res 1998;18(5A):3433-3437

25 Ginestra A, Miceli D, Dolo V, Romano FM, Vittorelli ML. Membrane vesicles in ovarian cancer fluids: a new potential marker. Anticancer Res 1999;19(4C):3439-3445

26 Dolo V, Ginestra A, Cassarà D, et al. Selective localization of matrix metalloproteinase 9 , beta1 integrins, and human lymphocyte antigen class I molecules on membrane vesicles shed by 8701 BC breast carcinoma cells. Cancer Res 1998;58(19):4468-4474

27 Dolo V, D’Ascenzo S, Violini S, et al. Matrix-degrading proteinases are shed in membrane vesicles by ovarian cancer cells in vivo and in vitro. Clin Exp Metastasis 1999;17(2):131-140

28 Angelucci A, D'Ascenzo S, Festuccia C, et al. Vesicle-associated urokinase plasminogen activator promotes invasion in prostate cancer cell lines. Clin Exp Metastasis 2000;18(2):163-170

29 Graves LE, Ariztia EV, Navari JR, Matzel HJ, Stack MS, Fishman DA. Proinvasive properties of ovarian cancer ascites-derived membrane vesicles. Cancer Res 2004;64(19):7045-7049

30 Lacroix R, Plawinski L, Robert S, et al. Leukocyte- and endothelialderived microparticles: a circulating source for fibrinolysis. Haematologica 2012;97(12):1864-1872

31 Lacroix R, Dignat-George F. Microparticles: new protagonists in pericellular and intravascular proteolysis. Semin Thromb Hemost 2013;39(1):33-39

32 Dejouvencel T, Doeuvre L, Lacroix R, et al. Fibrinolytic cross-talk: a new mechanism for plasmin formation. Blood 2010;115(10):2048-2056

33 Lijnen HR. Elements of the fibrinolytic system. Ann N Y Acad Sci 2001;936:226-236

34 Falati S, Liu Q Gross P, et al. Accumulation of tissue factor into developing thrombi in vivo is dependent upon microparticle Pselectin glycoprotein ligand 1 and platelet P-selectin. J Exp Med 2003;197(11):1585-1598

35 Thomas GM, Panicot-Dubois L, Lacroix R, Dignat-George F, Lombardo D, Dubois C. Cancer cell-derived microparticles bearing Pselectin glycoprotein ligand 1 accelerate thrombus formation in vivo. J Exp Med 2009;206(9):1913-1927

36 Khorana AA, Connolly GC. Assessing risk of venous thromboembolism in the patient with cancer. J Clin Oncol 2009;27(29):4839-4847

37 Khorana AA, Dalal M, Lin J, Connolly GC. Incidence and predictors of venous thromboembolism (VTE) among ambulatory high-risk cancer patients undergoing chemotherapy in the United States. Cancer 2013;119(3):648-655

38 Nomura S, Niki M, Nisizawa T, Tamaki T, Shimizu M. Microparticles as Biomarkers of Blood Coagulation in Cancer. Biomark Cancer 2015;7:51-56

39 van Es N, Bleker S, Sturk A, Nieuwland R. Clinical significance of tissue factor-exposing microparticles in arterial and venous thrombosis. Semin Thromb Hemost 2015;41(7):718-727

40 Thomas GM, Brill A, Mezouar S, et al. Tissue factor expressed by circulating cancer cell-derived microparticles drastically increases the incidence of deep vein thrombosis in mice. J Thromb Haemost 2015;13(7):1310-1319

41 Zwicker JI. Predictive value of tissue factor bearing microparticles in cancer associated thrombosis. Thromb Res 2010;125(Suppl 2): S89-S91

42 Jung T, Castellana D, Klingbeil P, et al. CD44v6 dependence of premetastatic niche preparation by exosomes. Neoplasia 2009; 11(10):1093-1105

43 Lo-Coco F, Ammatuna E. The biology of acute promyelocytic leukemia and its impact on diagnosis and treatment. Hematology (Am Soc Hematol Educ Program) 2006;•••:156-161, 514

44 Melnick A, Licht JD. Deconstructing a disease: RARalpha, its fusion partners, and their roles in the pathogenesis of acute promyelocytic leukemia. Blood 1999;93(10):3167-3215

45 Wang Z-Y, Chen Z. Acute promyelocytic leukemia: from highly fatal to highly curable. Blood 2008;111(5):2505-2515

46 de la Serna J, Montesinos P, Vellenga E, et al. Causes and prognostic factors of remission induction failure in patients with acute promyelocytic leukemia treated with all-trans retinoic acid and idarubicin. Blood 2008;111(7):3395-3402

47 Lehmann S, Ravn A, Carlsson L, et al. Continuing high early death rate in acute promyelocytic leukemia: a population-based report from the Swedish Adult Acute Leukemia Registry. Leukemia 2011; 25(7):1128-1134

48 Myers TJ, Rickles FR, Barb C, Cronlund M. Fibrinopeptide A in acute leukemia: relationship of activation of blood coagulation to disease activity. Blood 1981;57(3):518-525

49 Bauer KA, Rosenberg RD. Thrombin generation in acute promyelocytic leukemia. Blood 1984;64(4):791-796

50 Tallman MS, Lefèbvre P, Baine RM, et al. Effects of all-trans retinoic acid or chemotherapy on the molecular regulation of systemic blood coagulation and fibrinolysis in patients with acute promyelocytic leukemia. J Thromb Haemost 2004;2(8):1341-1350

51 Wang J, Weiss I, Svoboda K, Kwaan HC. Thrombogenic of cell undergoing apoptosis. Brit J Haematol 2001;115:382-391

52 Bennett B, Booth NA, Croll A, Dawson AA. The bleeding disorder in acute promyelocytic leukaemia: fibrinolysis due to u-PA rather than defibrination. Br J Haematol 1989;71(4):511-517

53 Tapiovaara $\mathrm{H}$, Matikainen S, Hurme $M$, Vaheri A. Induction of differentiation of promyelocytic NB4 cells by retinoic acid is associated with rapid increase in urokinase activity subsequently downregulated by production of inhibitors. Blood 1994;83(7): 1883-1891

54 Tapiovaara H, Alitalo R, Stephens R, Myöhänen H, Ruutu T, Vaheri A. Abundant urokinase activity on the surface of mononuclear cells from blood and bone marrow of acute leukemia patients. Blood 1993;82(3):914-919

55 Stephens R, Alitalo R, Tapiovaara H, Vaheri A. Production of an active urokinase by leukemia cells: a novel distinction from cell lines of solid tumors. Leuk Res 1988;12(5):419-422

56 Menell JS, Cesarman GM, Jacovina AT, McLaughlin MA, Lev EA Hajjar KA. Annexin II and bleeding in acute promyelocytic leukemia. N Engl J Med 1999;340(13):994-1004

57 O'Connell PA, Madureira PA, Berman JN, Liwski RS, Waisman DM. Regulation of S100A10 by the PML-RAR- $\alpha$ oncoprotein. Blood 2011;117(15):4095-4105

58 Meijers JC, Oudijk EJ, Mosnier LO, et al. Reduced activity of TAF (thrombin-activatable fibrinolysis inhibitor) in acute promyelocytic leukaemia. Br J Haematol 2000;108(3):518-523

59 Kwaan HC, Rego EM. Role of microparticles in the hemostatic dysfunction in acute promyelocytic leukemia. Semin Thromb Hemost 2010;36(8):917-924

60 Kwaan HC, Rego EM, McMahon B, Weiss I, Marvin J. Microparticles in acute promyelocytic leukemia. Blood 2011;118:3346 (Abstract)

61 Judicone C, Frankel D, Lacroix R, et al. Microparticles from Acute Promyelocytic Leukemia Generate Plasmin in Urokinase-Dependant Manner. ISTH 2016 SSC. 62, 2016/05/25-28, Montpellier, France; 2016 